\title{
ICT integration in schools: Where are we now and what comes next?
}

\author{
Colin Baskin \\ James Cook University \\ Michelle Williams \\ QSITE
}

\begin{abstract}
The case for more technology in schools is compelling. The leverage for a school based solution is traceable to the Common and Agreed National Goals for Schooling (AEC, 1989), namely that students will develop skills in 'information processing and computing'. Schools have wrestled with this 'integration challenge' since 1989. This paper is a snapshot of the ICT efforts of 18 regional schools as they come to terms with the challenge of ICT integration. Building on the work of Lim et al (2003), and the JISC (2003) MLE benchmark study, this paper profiles what ICT integration looks like in schools since AEC (1989), identifying 'administrative imperatives' as the key factors underpinning ICT integration decisions in schools.

In terms of capacity management, the paper identifies those who plan, design, develop and build school ICT infrastructure. Each school participating in this study is assigned an integration score, identifying them as low, medium or high integration schools based on ICT integration efforts. Evidence from this study indicates a great deal of ICT integration development and activity taking place in schools at all integration levels. The good news is that national and state education initiatives over the last 17 years have delivered an integration (of sorts) of ICTs into compulsory education. The sad news is that the question of ICT pedagogy remains largely unaddressed in our schools.
\end{abstract}

\section{Schools and ICT integration: The Australian policy context}

Australian national and state education initiatives over the last 25 years stress the integration of computing technologies into compulsory education (AEC 1989; State of Victoria, 2001; Tas 2002; MCEETYA 2003; 2005). Like Western governments worldwide, in Australia computing technologies are considered a motherhood solution to the needs of a highly skilled and technologically capable workforce. Implicated in this 'final solution' is 
compulsory school education and its connection to future workplaces. The 2005 MCEETYA Joint Statement on Education and Training in the Information Economy resonates with this kind of digital rhetoric as we move towards a "...leading edge education and training system" that "drives development of an innovative society" (MCEETYA, 2005). ICTs (information and communication technologies) in education are burdened with the promise "to raise education standards and minimum skill levels" marking the arrival of the "future economy". The "quality training through new technologies' of this new legion of workers will address Australia's need for competent, lifelong learners in "a world of continuous technological change where knowledge is becoming a commodity" (MCEETYA, 2005).

The cry for more technology in schools is deeply connected here; the origins of a school based solution are traceable to the Common and Agreed National Goals for Schooling (AEC, 1989), which included the goal that students develop skills in 'information processing and computing'. In 2005, MCEETYA released its Joint Statement on Education and Training in the Information Economy, proclaiming a new blueprint for ICTs to 'empower' teachers and raise the standards of students' learning outcomes. The 16 year period between AEC (1989) and MCEETYA (2005) is a telling one; espoused views on computing technologies and student learning shifted from an initial preoccupation with the teaching of computer skills, to focus more on issues of ICT access for all students (MCEETYA, 1999), the relevance of a 'whole school' approach to ICT teaching and learning (Curriculum Corporation, 2003), and more recently to issues of school based change management and teacher professional development (Henderson, 2004). If we listen closely to this shifting 'learnscape', we can discern a quiet mantra: in terms of ICTs in schooling, more is definitely better.

In Learning in an online world (MCEETYA, 2000) evidence of a governance approach to integrating 'more ICTs in schools' can be found. Iterations of what it means to integrate ICTs are rolled out as a suite of statements and frameworks including the Online Content Strategy (2004); Learning Architecture Framework (2003); Research Strategy (2003); and Bandwidth Action Plan (2003). Notably, a Pedagogy and a Leadership and Professional Learning Strategy (2005) earmark a new direction in ICT statements for schools. This is notable for two reasons; (1) until this release, pedagogy has been a silent space in the evolution of ICTs in schools, and; (2) leadership has for the first time been problematised in the ICTs in schools debate.

\section{Teachers, learners and ICT uptake in schools}

This is a significant shift in emphasis; historically, existing digital rhetoric (particularly in relation to teacher professional development here in 
Queensland) foregrounds the 'use' of ICTs and locates learners, teachers and ICT leaders as 'users' of technologies. Teacher ICT competency has in the past been likened to a 'skills continuum', embedded in school based ICT professional development - teachers must be willing to adapt to change, assemble reasonable ICT competencies, and demonstrate capacity for time management (Guha, 2003; Bitner \& Bitner, 2002). Not only must the teacher have access to a 'working' ICT tool kit, but this skill set must be matched by pedagogical compatibility, and social awareness (Zhao, Pugh, Sheldon \& Byers, 2002). Variations in access to ICTs and levels of school based ICT infrastructure are also critical to the successful uptake of ICTs in the classroom (Loveless, 1996); this is deeply connected to levels of teacher and systems support, such that the stronger the ICT culture of a school, the more likely it is to 'use' ICTs as a teaching and learning platform (Lim, Khine, Hew, Wong, Shanti \& Lim, 2003; Bitner \& Bitner, 2002).

This 'user' mindset positions school based users of ICTs within a broader administrative set of relations, encompassing service level relationships based on identified client needs. The problem with being an ICT client in contemporary schools is that clients are 'done to' and 'done for'; they are not expected to impose themselves on the technology, but are much more expected to have the technology imposed on them. Technology is at risk of becoming utilitarian; ICT integration in practice means gravitation to prescribed technological norms of use and performance, and an abeyance and deference to user protocols and proprietary ICT desktop standards. Certainly, there will be more people in schools using technology but this use will be patterned rather than inspired, reactive rather than proactive, and reproductive rather than creative (Cuban, 2001). In Telling Tales out of School: Why ICT is Problematic, Mark Brown (2004) of Massey University (NZ) challenges this context of ICT 'use' in schools, pointing to ICT integration as multifactorial, in so far as it must involve:

- Curriculum integration - how ICTs relate to school based curriculum goals and content.

- Spatial integration - how ICTs are embedded in classroom learning activities.

- Temporal integration - how ICT activity connects to established learning activities.

- Pedagogical integration - how ICT choices constructively align with teaching approaches; and:

- Attitudinal integration - the extent to which ICTs are considered problematic by teachers and students.

In a personal communication (July, 2005), Brown concludes "Of course, there is still an implicit assumption embedded within these categories that integration is the ultimate goal and they offer no explicit recognition of the 
need for teachers to go beyond what is currently possible by reconceptualising the curriculum itself". Thus it can be said, that the management and marshalling of resources to achieve desired as well as mandated school based ICT outcomes is a significant challenge facing schools (Lim et al, 2003). This paper looks at the material effects of this challenge as it impacts on 18 local schools on the Queensland seaboard. It poses, and investigates, some important and fundamental questions about ICT integration in these schools.

1. What does ICT integration look like in local schools given the current policy context?

2. Which factors influence ICT integration decisions within local schools?

3. To what extent are local schools keeping pace with national ICT policy?

4. Who makes ICT integration decisions in these schools?

5. Who develops the ICT infrastructure that emerges from these decisions?

6. What kind of regional ICT network are we building?

\section{Participating schools}

This project features a convenience sample of regional secondary and primary schools. In total, 25 schools were approached to participate in the pilot study, with the first 20 respondent schools accepted into the study; 18 completed data sets were confirmed. These 18 schools forming the study, ranged in size from 153 primary students to 1500 secondary students, and were located between Cooktown in Far North Queensland, and the Sunshine Coast in South East Queensland. The sample demographics are listed in Table 1.

Table 1: Type of school and affiliation

\begin{tabular}{|l|l|c|}
\hline \multicolumn{2}{|l|}{ Type of school } & Sample \% \\
\cline { 2 - 3 } & Srimary school & 37.5 \\
\hline \multirow{2}{*}{$\begin{array}{l}\text { Affiliation of } \\
\text { school }\end{array}$} & State high school (SHS) & 62.5 \\
\cline { 2 - 3 } & State primary school (SPS) & 43.75 \\
\cline { 2 - 3 } & Non-state high school (NSHS) & 31.25 \\
\cline { 2 - 3 } & Non-state primary school (NSPS) & 18.75 \\
\hline
\end{tabular}

\section{The technologies in use}

Like school clusters anywhere in Australia, a range of technologies are in use across the cohort. These technologies enable ICT activities that are supported through online networks and databases. These include record keeping (students' attendance, student achievement outcomes, finance and asset management); information provision (newsletters and daily bulletins); communications (email, discussion boards, blogcasts and 
podcasts); online content (accessible over the Internet); and library borrowing. In some schools, computers are linked to the Internet through telecommunications services including high speed broadband, dialup and through satellites; wireless technologies; personal digital assistants (PDAs) and handheld devices such as notebooks and laptops. Some schools in the sample are trialing interactive whiteboards, while others are reintroducing blackboards. Both synchronous and asynchronous (the majority of cases) software is used to support online exchange between both learners and teachers. In all instances in the survey, the computing infrastructure and architecture provisions of participating schools included the hardware, software, intranet and Internet services, networking and connectivity requirements necessary for the teaching, learning and administration of schools.

\section{Instrumentation}

Given the range of technologies at work in these schools, two major studies (JISC, 2003; Lim et al, 2003) informed and influenced the inquiry method underpinning this study. The JISC (2003) ICT benchmark study was an extensive, cross-sectorial survey of the compulsory and post-compulsory schooling sectors in the United Kingdom, with a specific focus on Managed Learning Environments (MLEs). Any organisation with a proprietary finance, human resource or learning management system is said by definition to have embarked on the development of a managed learning environment (Baskin \& Anderson, 2003). The JISC (2003) study focused on all aspects of ICT integration in schools, drawing clear distinctions between business critical and learning oriented ICT adoptions. Lim et al (2003) contextualised this in their study of Singaporean schools, examining the key factors influencing ICT integration in Singapore schools, pointing towards a 'managed approach' to more effective ICT integration in schools. Like both JISC (2003) and Lim et al (2003), this study adopted an extensive survey instrument that measured 22 pages in length, and involved a twohour structured interview to administer with the ICT leadership of each of the participating schools (see Figure 4 below).

The survey instrument comprised eight distinct domains (Table 2), each domain with defined question sets, numbering 22 question sets/variables in total. These questions involved both quantitative (rankings, ratings, forecasts) and qualitative (open ended questions and diagrams) data moves, in a bid to explicate ICT integration efforts in these 18 schools. In total, the instrument delivered 1912 data bytes per school over the eight questionnaire domains (Table 2) in response to 22 question sets regarding ICT practices within participating schools. 
Table 2: Data collection techniques

Key: 1 = Ranking items. 2 = Rating items. 3 = Forecasts.

$4=$ Open ended responses. $X$ indicates non-use of technique.

\begin{tabular}{|c|c|c|c|c|c|}
\hline Question domain & Question sets/variables & 1 & 2 & 3 & 4 \\
\hline \multirow{4}{*}{$\begin{array}{l}\text { Network use, } \\
\text { extent and health }\end{array}$} & Monitoring of ICT use/performance & $\sqrt{ }$ & $\sqrt{ }$ & $\sqrt{ }$ & $\mathrm{X}$ \\
\hline & Variety-learner collaborations & $\sqrt{ }$ & $\sqrt{ }$ & $\mathrm{X}$ & $\sqrt{ }$ \\
\hline & Teacher integration ICTs - curriculum & $\sqrt{ }$ & $\sqrt{ }$ & $\sqrt{ }$ & $\sqrt{ }$ \\
\hline & Teacher/learner access to ICTs & $\sqrt{ }$ & $\sqrt{ }$ & $\sqrt{ }$ & $\sqrt{ }$ \\
\hline \multirow{5}{*}{$\begin{array}{l}\text { ICTs in learning } \\
\text { and teaching }\end{array}$} & ICT leadership - teaching & $\sqrt{ }$ & $\sqrt{ }$ & $\sqrt{ }$ & $\sqrt{ }$ \\
\hline & Pupil ICT proficiency & $\sqrt{ }$ & $\sqrt{ }$ & $\sqrt{ }$ & $\mathrm{X}$ \\
\hline & Learner use of ICTs & $\sqrt{ }$ & $\sqrt{ }$ & $\sqrt{ }$ & $\sqrt{ }$ \\
\hline & ICTs \& higher order thinking & $\sqrt{ }$ & $\sqrt{ }$ & $\mathrm{X}$ & $\sqrt{ }$ \\
\hline & Teacher proficiency & $\sqrt{ }$ & $\sqrt{ }$ & $\sqrt{ }$ & $\mathrm{X}$ \\
\hline ICTs school admin & ICT leadership - school administration & $\sqrt{ }$ & $\sqrt{ }$ & $\sqrt{ }$ & $\sqrt{ }$ \\
\hline \multirow{2}{*}{$\begin{array}{l}\text { ICT school } \\
\text { management issues }\end{array}$} & Collegial sharing - ICT experiences & $\sqrt{ }$ & $\sqrt{ }$ & $\sqrt{ }$ & $\sqrt{ }$ \\
\hline & ICT innovation & $\sqrt{ }$ & $\sqrt{ }$ & $\sqrt{ }$ & $\sqrt{ }$ \\
\hline \multirow{3}{*}{$\begin{array}{l}\text { ICT decision } \\
\text { management issues }\end{array}$} & School ICT policy & $\sqrt{ }$ & $\sqrt{ }$ & $\mathrm{X}$ & $\sqrt{ }$ \\
\hline & ICT program review & $\sqrt{ }$ & $\sqrt{ }$ & $\sqrt{ }$ & $\sqrt{ }$ \\
\hline & Staff involvement ICT planning & $\sqrt{ }$ & $\sqrt{ }$ & $\mathrm{X}$ & $\sqrt{ }$ \\
\hline $\begin{array}{l}\text { Technical issues / } \\
\text { standards }\end{array}$ & ICT systems embeddedness & $\sqrt{ }$ & $x$ & $\sqrt{ }$ & $\mathrm{X}$ \\
\hline \multirow[t]{3}{*}{ Systems integration } & ICT systems connectivity & $\sqrt{ }$ & $\sqrt{ }$ & $\sqrt{ }$ & $\sqrt{ }$ \\
\hline & ICTs and learner collaboration & $\sqrt{ }$ & $\sqrt{ }$ & $\sqrt{ }$ & $\sqrt{ }$ \\
\hline & Teacher ICT collaborations & $\sqrt{ }$ & $\sqrt{ }$ & $\sqrt{ }$ & $\sqrt{ }$ \\
\hline \multirow{3}{*}{$\begin{array}{l}\text { Staff training and } \\
\text { development }\end{array}$} & Staff ICT integration skills & $\sqrt{ }$ & $\sqrt{ }$ & $\sqrt{ }$ & $\sqrt{ }$ \\
\hline & $\begin{array}{l}\text { Teaching- role of ICTs in higher order } \\
\text { thinking }\end{array}$ & $\sqrt{ }$ & $\sqrt{ }$ & $\sqrt{ }$ & $\sqrt{ }$ \\
\hline & Staff ICT skills development opportunities & $\sqrt{ }$ & $\sqrt{ }$ & $\sqrt{ }$ & $\sqrt{ }$ \\
\hline
\end{tabular}

\section{Ranking participating schools based on ICT integration}

In line with related studies (JISC, 2003; Lim et al, 2003) the survey data was used to identify and 'rank' participating schools in banded levels of ICT integration and network performance. Ranking would enable some macro level comments on what ICT integration looks like in local schools given the current policy context, and enable some understanding of the factors driving ICT integration decisions within local schools. Participating schools, along with their banded ICT integration scores are presented in Table 3. While every effort is made to ensure the confidentiality of schools, their affiliations (as state or non-state schools / primary and/or secondary schools) are contained in the table.

The basis for ranking was the relative level of integration of teaching, learning and administrative systems within the school, as reported in survey outcomes. School responses to the survey were used to derive an 'integration score' (Lim et al, 2003) for each current school situation (Table 4). The integration score was expressed as a percentage score, based on the 
sum of the individual variables over the maximum possible score. Each variable was scored from 1 (low level integration) to 5 (high level integration) over 22 question sets (see Table 3), and the individual values were summed to give an integration score (Table 4). There were 22 question sets in the survey, giving a maximum score of 110 . The percentage score was used to rank and band participating schools. Means and standard deviations were calculated for each school across the 22 components of the study. The resultant integration scores were then banded into three distinct groups (low, medium and high levels) of ICT/systems integration based on current school situations. As seen in Table 3, all high integration schools are secondary schools; medium integration schools and low integration schools contained a mix of state and non-state high schools and primary schools, with the latter predominantly primary schools. A one way independent ANOVA was used to ascertain which if any of the 22 component questions (cited in Table 2) were significant as variables in identifying low, medium and high integration schools.

Table 3: School spread by integration scores

\begin{tabular}{|l|l|l|l|}
\hline & $\begin{array}{l}\text { Low ICT/ systems } \\
\text { integration }\end{array}$ & $\begin{array}{c}\text { Medium ICT/ } \\
\text { systems integration }\end{array}$ & $\begin{array}{l}\text { High ICT/ systems } \\
\text { integration }\end{array}$ \\
\hline $\begin{array}{l}\text { ICT integration } \\
\text { score 70- upwards }\end{array}$ & $\begin{array}{l}\text { Swanfield SHS } \\
\text { Ergonnan SHS } \\
\text { Kwality SHS } \\
\text { St Maddies NSHS } \\
\text { South Park SHS }\end{array}$ \\
\hline $\begin{array}{l}\text { ICT integration } \\
\text { score 55-69 }\end{array}$ & $\begin{array}{l}\text { Canes SHS } \\
\text { Anglophile NSHS } \\
\text { Fudge Hill SPS } \\
\text { Weary SPS } \\
\text { Weary SHS }\end{array}$ & \\
\hline $\begin{array}{l}\text { ICT integration } \\
\text { score 54- below }\end{array}$ & $\begin{array}{l}\text { St Throms NSPS } \\
\text { Pitta Park PS } \\
\text { Topity Bay SHS } \\
\text { Blackrock PS } \\
\text { St Molly's NSHS } \\
\text { Hoppleton SPS }\end{array}$ & & \\
\hline
\end{tabular}

\section{Results}

\section{ICT Integration in local schools}

Figure 1 (below) presents a comparison of means for each of the 22 variables (Table 2). Low, medium and high integration schools are clearly discernible through this comparison, showing clear differences in patterns of ICT integration amongst low, medium and high integration schools. This 
serves as a visual representation of what ICT integration looks like in local schools, given the current policy context.

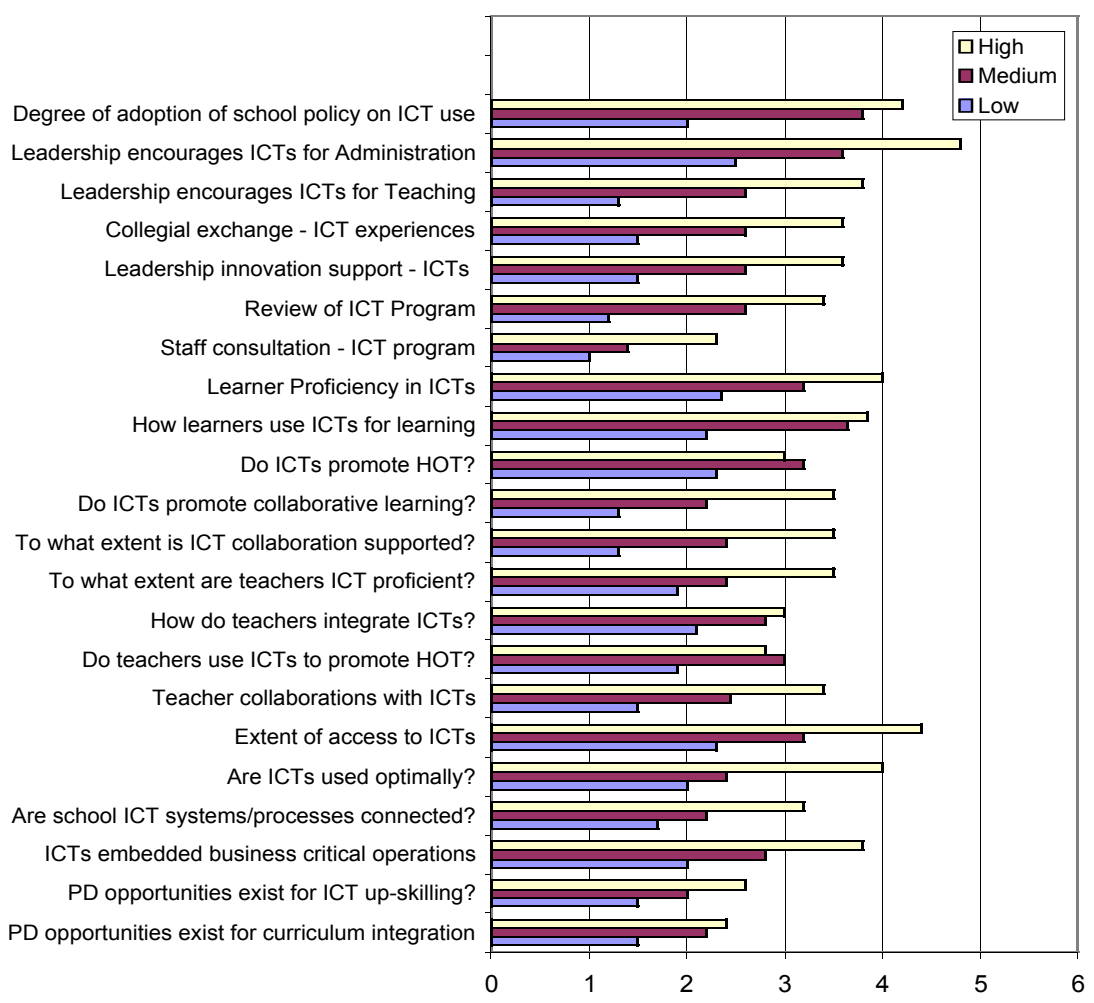

Figure 1: Comparison of means -22 aspects of ICT/ systems integration derived from Table 2.

It also identifies the factors that influence ICT decision making in schools. Results of the ANOVA confirm that 6 out of 22 variables are significant in discriminating between schools as low, medium or high integration sites. In order of effect size, these are:

1. Collegial exchange about ICT knowledge and experiences $\mathrm{F}(2,15)=5.00$, $\mathrm{p}<0.05, r=0.74$

2. Monitoring for optimal use of ICT resources $F(2,15)=3.987, p<0.05$, $r=0.71$

3. The extent of ICT policy adoption across the school $\mathrm{F}(2,15)=3.83$, $\mathrm{p}<0.05, r=0.70$;

4. School review cycles for ICT policy $\mathrm{F}(2,15)=3.733, \mathrm{p}<0.05, r=0.69$ 
5. The embeddedness of ICTs in school core business critical practices $\mathrm{F}(2,15)=3.83, \mathrm{p}<0.05, r=0.68$, and

6. Leadership support - ICT uptake for administration $\mathrm{F}(2,15)=3.43$, $\mathrm{p}<0.05, r=0.64$.

\section{What ICT infrastructure are schools building?}

The survey found significant levels of ICT activity across the sample, including school intranet development across all participating schools. Over $75 \%$ of schools in the study were currently engaged in some kind of intranet development activity (Figure 2), while $25 \%$ of all respondent schools reported no real work done or planned in this area (over the next 2 years at least). Of the active $75 \%$ of schools, $50 \%$ have work planned but are at the early stages of this cycle.
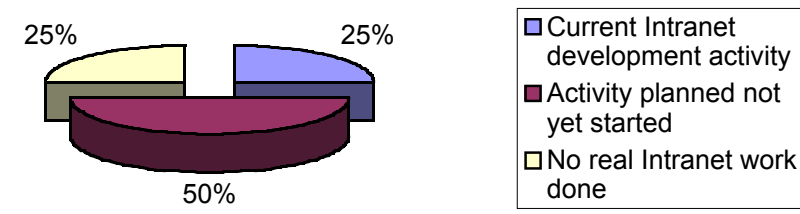

Figure 2: ICT and systems development activity in the sample

\section{Who is doing the ICT infrastructure development?}

Figure 3 indicates the diversity of solutions adopted across the region, and also indicates the importance of customisation and development to meet specific institutional circumstances. Some $48 \%$ of all participating schools have developed software in house, and over $40 \%$ used proprietary or off the shelf software with local customisation and development. With 35\% of schools not yet attempting interoperability, centrally provided software and support forms the basis of most school software architecture and systems infrastructure. Of the 19\% of schools undertaking in house development of ICT and intranet activity, all are relying on current IT department staff to complete this work. In all cases, the development would most likely cease if the staff member involved was to face a transfer or change of school. Of the 35\% of schools not yet attempting interoperability, one of the major impediments to continued ICT and intranet development activity, was the 'messy' system currently in place. As one IT coordinator put it, "...it's like working with a house of cards... move the wrong one and it all comes down". 

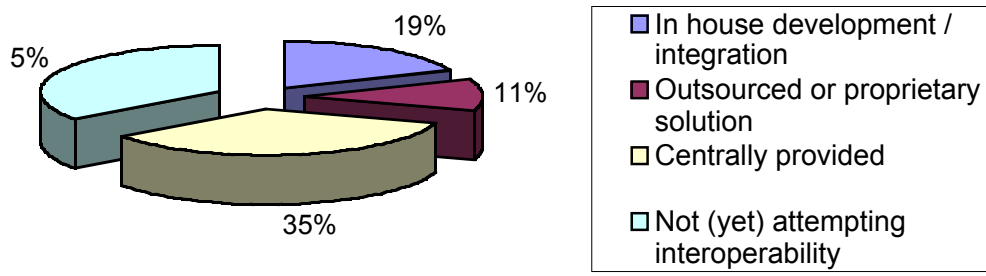

Figure 3: Operational models for ICT/intranet development

\section{Decision making, ICT and intranet development in schools}

The key issue across participating schools is the need to embed development efforts firmly within a wider policy and strategic school context. As reflected in Figure 4, the IT head of department (HOD) is a singularly influential character in the ICT decision making tree in schools $(32 \%)$. In $25 \%$ of cases, the IT HOD made formal recommendations to a working committee built around the ICT planning processes of the school. These recommendations were then matched against the ICT plan of the school and actioned accordingly. In a further $30 \%$ of cases, the school leadership group made executive decisions about the ICT infrastructure and architecture of the school.

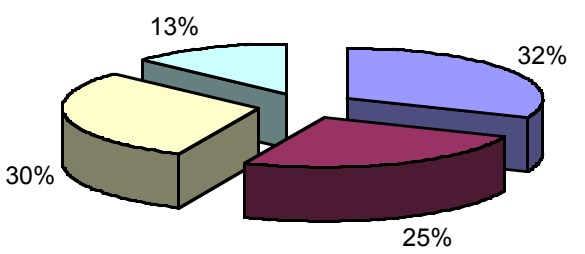

口The IT HOD makes all decisions

$\square$ The IT HOD recommends to a committee

$\square$ School leadership group makes decisions

$\square$ School internal/external consultative group makes decisions

Figure 4: Decision-making trees for ICT/intranet developments in schools

\section{Constraints and barriers to ICT development and integration}

There is considerable unanimity in the data to suggest that there are major constraints on and barriers to further ICT developments in the host schools. Significant constraints or barriers (ranked in order of importance across participating schools) include the lack of teacher knowledge about ICTs, the lack of teacher professional development in ICTs for teaching, and the lack of support staff to facilitate sustainable professional development. 
Table 4: ‘Considerable barriers' to ICT development in schools

\begin{tabular}{|l|c|c|c|}
\hline \multicolumn{1}{|c|}{ Barriers } & $\begin{array}{c}\text { Low } \\
\text { integration } \\
\text { schools }\end{array}$ & $\begin{array}{c}\text { Medium } \\
\text { integration } \\
\text { schools }\end{array}$ & $\begin{array}{c}\text { High } \\
\text { integration } \\
\text { schools }\end{array}$ \\
\hline Lack of time & $88 \%$ & $92 \%$ & $56 \%$ \\
\hline Lack of money & $84 \%$ & $72 \%$ & $32 \%$ \\
\hline Lack of incentives & $72 \%$ & $64 \%$ & $56 \%$ \\
\hline Lack of teaching staff knowledge & $84 \%$ & $80 \%$ & $80 \%$ \\
\hline Lack of teaching staff development & $76 \%$ & $88 \%$ & $80 \%$ \\
\hline Lack of support staff & $88 \%$ & $60 \%$ & $72 \%$ \\
\hline Current organisational structure & $64 \%$ & $40 \%$ & $32 \%$ \\
\hline Technical problems & $64 \%$ & $40 \%$ & $28 \%$ \\
\hline $\begin{array}{l}\text { Too many/ diffuse/ diverse } \\
\text { standards and guidelines }\end{array}$ & $32 \%$ & $36 \%$ & $32 \%$ \\
\hline Too few standards and guidelines & $32 \%$ & $36 \%$ & $28 \%$ \\
\hline
\end{tabular}

\section{Discussion: What does ICT innovation look like in schools and who drives it?}

The skill and attitude of the teacher is a key determinant in the effectiveness of technology integration into the curriculum (Bitner \& Bitner, 2002). Accepted wisdom has it that once the teachers assemble ICT skills, they begin to find ways to integrate technology into their curriculum and demonstrate its use to others. But what happens when teaching and learning is not the core lens through which schools view ICT integration efforts? Collegial exchange about ICT knowledge and experiences has the strongest effect size in this study, and therefore the strongest effect on ICT integration levels in participating schools. This is not to suggest however that teachers are necessarily engaged in a great deal of professional 'talk' about the integration of ICTs in schools, curriculum and pedagogy. Collegial exchange about ICT knowledge and experiences usually transpires in the context of ICT planning and professional development. These planning and development sessions are the responsibility of the school administration and management team, so the sharing and exchange that transpires within schools, usually relates to the 'sharing' of top down knowledge and experience about ICTs. More often than not, this is connected to administrative views about ICT solutions in schools.

Most collegiate exchange around ICTs in this study was initiated by the head of department - information technology, and enacted as school based professional development. This trend is illuminated by other significant findings in this study. Trend analysis captures a centralised view of administrative systems, processes, planning and capacity that drives the school ICT vision, placing a heavy emphasis on ICT policy adoption $(\mathrm{F}(2,15)=3.83, \mathrm{p}<0.05, r=0.70)$; frequent ICT policy review $(\mathrm{F}(2,15)=3.733$, $\mathrm{p}<0.05, r=0.69)$; leadership support for ICT led administration $(\mathrm{F}(2,15)=$ 
3.43, $\mathrm{p}<0.05, r=0.640)$; and reporting compliance through data driven core business critical functions $(\mathrm{F}(2,15)=3.83, \mathrm{p}<0.05, r=0.68)$. That collegial exchange of ICT experiences is a key feature of local schools is incredibly positive; computer networks are inherently social networks, linking people, organisations and knowledge into an integrated framework for everyday practice (Wellman, 2001), but this connection is contingent upon the culture and setting of the school. If learning is the impetus that drives the use of technology in schools, then teachers and students ought be partners in the learning process, altering traditional paradigms of the teacher providing wisdom and the student consuming knowledge. This appears not to be the case in this study; the policy call for deeper integration of computing technologies into compulsory education (AEC 1989; State of Victoria, 2001; Department of Education, Tasmania, 2002; MCEETYA, 2003, 2005) seems to have faltered at the school site.

A reverse trend analysis supports the contention that neither teacher integration of ICTs into the curriculum, nor staff ICT skills development were contributing factors to the ICT integration rating of participating schools. In fact, none of the teaching and learning variables in this study (Table 2) are significant to school ICT integration scores, locating teaching and learning at the periphery of ICT development activity in these schools. This is a compelling finding, given the current national policy context for ICTs in schools. This trend is further exacerbated in data related to teacher and learner competence in ICTs as influencers of school ICT integration rankings. Both teacher and learner competence are directionally strong results for schools in this study; yet neither is significantly influential on school integration scores. The school focus on administration as the frame for critical ICT integration outcomes for schools is reflected in weak school leadership support for ICTs in teaching, and low innovation and experimentation with ICTs scores. Staff adoption of ICT policy, ICT program review procedures, and the degree of leadership support for ICT led administration has embedded ICTs in the critical business functions of each school. ICTs are part of the capacity management process of schools, and collegial exchange of ICT experiences is predicated on a model of staff PD (professional development) wherein most PD is run in house by system and school administration teams, to improve access by staff to existing ICT resources within the school.

\section{Schools keeping pace with national policy: ICT infrastructure and development}

The survey found significant levels of ICT activity across the sample, including $75 \%$ of schools in the study disclosing some kind of intranet development in the foreseeable two year future (Figure 2). The study successfully demarcated between low, medium and high integration 
schools in a way that locates each of the schools at different points within existing national and state ICT policy agendas (AEC 1989; State of Victoria, 2001; Tas 2002; MCEETYA 2003; 2005). In terms of a planning hierarchy, the level playing field seems to have evaporated. In ascending order, Low integration schools expressed interest in developing the ICT basics:

- Staff access to institutional information

- Staff access to course administration

Medium integration schools expressed an interest in developing some degree of systems interoperability:

- Access to subject description and learning outcomes

- Tracking students' attendance

- Fee payment

- Access to assessment results

- Student and staff portals

- Accessibility of resources for students with disabilities

High integration schools expressed an interest in developing high end user differentiation and capacity:

- Staff access to institutional information

- Staff development

- A capacity for student enrolment

- Personalised access to electronic learning resources

- Student access to library or learning resource centre

- Student access to administrative data

- Monitoring students' use of online resources

- Support for users of electronic learning resources

Figure 3 indicates the diversity of solutions adopted across the local region, and also indicates the importance of customisation and development to meet specific institutional circumstances. With $48 \%$ of all participating schools having developed software in house, and over $40 \%$ using proprietary or off the shelf software with local customisation, the chances of an integrated interoperable regional platform seems many years away. The continued reliance on centrally provided software continues to commit many schools in the medium and low integration sectors to an ICT infrastructure predicated on administrative and compliance reporting. All of the 18 schools in this study had membership access to the Learning Place as a source of professional development and renewal. Only four schools reported accessing these resources, and only one school accessed these resources more than once. This is indelibly connected to a resounding sense of the failure of school based leadership to promote ICTs for teaching and learning. 


\section{Decision making, ICT integration and development in schools}

Underpinning the study is an awareness of the differing perspectives usually held by network managers and teachers. Barone and Hagner (2000) describe the characteristics of 'the two cultures' hobbled with views that 'prevent much influence of one by the other'. They suggest the ICT culture is attuned to the whole system and the whole organisation (a strength of their perspective), wanting to prevent dangers, striving for focus and consistency (at odds with other views) and wanting decisions that concentrate resources and effort (cognisant of their capacity to deliver). In contrast, teachers in this study speak in idioms about how they work, the jobs they do and the culture they want to create around their work and the learning of their students. They are used to professional autonomy and not comfortable with outside agents influencing learning environments.

This study reveals that each group has presumptions about change that fuel these divisions. Teachers have a liberal presumption that there is a need to invent and experiment for advancement of pedagogical ideas and this includes wanting to try new ideas with ICT tools. ICT managers, on the other hand, have a conservative presumption, where change is determined by deliberation and that services need to be proven before being implemented on a general basis. Barone and Hagner (2000) suggest that leadership is necessary to resolve the cultural tension, and that critical discussions need to 'make space' for a range of views in circumstances where not everyone agrees on what needs to be transformed, or the strategies to drive such change. In the school community, these differing tensions often reside in the one person, particularly in participating primary schools. All ICT managers in this study also double as teachers. They report having inadequate time to undertake the role of network designer and manager, but strive to establish conditions in schools which best fit everyone's needs.

Opinion varies amongst this cohort about whether teachers can bridge the gap between the culture of IT management and the culture of the pedagogical and curriculum rationales which frame teacher perspectives. At this stage, the 'gatekeeper' appears to be winning the ideological battle in schools. Data from this study suggests school based ICT coordinators have developed more of an ICT management perspective, even though their practice in their classrooms was pedagogically sound. Further, this study suggests that the existing culture of the school community is yet to host conversations about the impact of the ICT pedagogy movement on the future demands of school network designs. In all instances in this survey, the ICT HOD formed part of the membership of the school leadership group. In $87 \%$ of cases, the IT HOD is directly involved in the planning and coordination of ICT and intranet development activities in schools. In 13\% 
of cases, no member of staff was able to account for ICT decisions that had been taken (or not taken) in relation to existing processes and systems. In each of these cases, the initiative or innovation had been the product of a staff member who had 'passed on' to another school.

\section{What ICT network are we building? Constraints and barriers to ICT integration}

Not surprisingly, the human factor is perceived as the most critical in nurturing the ICT culture and growing the critical mass of teachers (Rogers, 1995) able to sustain the use of ICTs effectively in their teaching. In low integration schools, this is compounded by low capacity perceptions (reflected in high money, time, support, technical problems and lack of incentive ratings). In all schools, however, there is an acknowledgement that teaching staff represent the greatest challenge to school renewal and ongoing ICT integration. The lack of a perceived incentive to self develop ICT capacity is strong across all schools, but compelling in low integration schools. In high and medium integration schools the current organisational structure is perceived as supportive of ongoing ICT staff and systems integration. In low integration schools the current organisational structure (read school based management team) are perceived to perpetuate ongoing ICT problems; with this perception comes the reality of increased technical problems. The corollary of this is that schools that are struggling to implement and integrate ICTs face the additional burden of increased professional development costs (time and support capacity). The glaring lack of support staff reaches crisis point, as schools descend down the ICT integration scale, from high, to medium to low integration status. The lack of support staff at the low integration level further compounds with problems related to capacity, that is, resources, money, support, expertise, and lack of incentive resulting in an ever decreasing circle of opportunity (Lim et al., 2003; Guha, 2003; Zhao et al., 2002; Bitner \& Bitner, 2002).

High integration schools perceived more incentives to proceed with further ICT and intranet developments, and believe they have the money and comparative resources to do it. For example, two of these schools had already engaged in external partnerships and consultations. Organisational structures in these schools are not considered to be a liability in the same way as in low integration schools, despite the realisation among many high end schools that ICT development requires a very fundamental rethink of institutional business processes and procedures. Technical constraints and standards issues were not a major priority for many schools in this study, and were therefore painted as 'less problematic' to schools, but nonetheless have deeper implications for platform interoperability across the region. The robustness of IT infrastructure and systems also emerges as a real concern as system components are integrated. Many primary schools still 
run dual Apple and Windows networks to provide administrative (Windows) as well curriculum (Apple) functionality, but lack the time, resources and expertise to address risks to system and data security.

All medium and low integration schools reported turnover of key ICT staff and systems in the last 3 years. While the integration scores differentiate between schools, and school ICT integration and intranet development needs, a basic typology exists here (Rogers 1995; Hagner \& Schneebeck, 2000). Low integration schools report higher relative time, money, human capital, knowledge, and incentive and skills barriers than do medium and high integration schools. The scale of the integration task is clearly daunting to many schools. There is a growing awareness of how large the training and professional development needs are, not only in relation to pedagogy, curriculum change, IT skills and awareness, but also in relation to wider 'cultural change' issues, as school systems develop and roll out new systems and processes over time. At the heart of these findings is an emerging digital divide: of the low integration schools, four have an Indigenous population greater than $33 \%$ of the student group, one is an all girl Catholic secondary college, and the remaining school is a Catholic primary school. Rarely does technology appear in this study as a tool for innovation; rather schools are using technology to sustain existing patterns of schooling and its connections to social opportunity (Conlon \& Simpson, 2003).

\section{Conclusion: Where to from here?}

National and state education initiatives over the last 25 years have delivered an integration (of sorts) of computing technologies into compulsory education. Evidence from this study shows that there is a great deal of ICT integration and intranet development activity taking place in schools at all levels. Learning in an online world (MCEETYA, 2003) has delivered the protocols for an ICT rollout strategy that has enabled schools to build capacity in Content (2006); Learning Architecture (2003); Research Strategy (2003); and Bandwidth (2003). This study successfully differentiates school efforts to respond to each of these pressures, while pointing to an overall sense in participating schools that ICT integration and development effort is a 'good thing'. It is broadly accepted by all participating schools that ICTs will at some stage of evolution provide accessible, flexible learning experiences, increased administrative efficiency, integration of functions, and improved processes across the school, despite the fact that few schools in this study have tangible experience of these advantages. There is also an emerging consensus that ICTs are 'the way forward' and will provide long term advantages, such as improving reporting processes, compliance procedures, managing data costs, and widening participation access. This acceptance exists despite the fact that the low integration 
schools that most need to accrue these benefits, are furthest away from accessing them. In low integration schools there is a sense of impending panic in the 'smart classroom' that because everyone else is going down this road, schools must follow or be left behind.

The data emerging from this project confirms a silence in our schools on the issue of pedagogical leadership in ICT teaching. What is also not apparent in participating schools is any real sense that ICTs are as yet fully embedded as interoperable and integrated strategic and operational frameworks (the limited e-learning environments utilised by schools in this study are restricted to experiments by ICT Heads of Department). All schools have an ICT development planning process, but for many this is a transparent, box ticking exercise that delivers few consumables other than central office compliance. Only in high integration schools are ICT activities included in a variety of strategic planning documents, but it is hard to identify any examples where ICTs are yet an integral part of the curriculum philosophy, policies and practice of the school.

George Siemens $(2004, \mathrm{p} 6)$ confirms that we have been slow to recognise the impact of ICTs as a new learning tool, and even slower "to recognise the environmental changes in what it means to learn". Brown (2004) challenges us to conceive new understandings of the complexity of integration, one which would enable the social and cultural shifts required to convert local school ICT practices into a managed platform for curriculum innovation and school renewal. Much ICT decision making in schools has been referred to the IT HOD in consultation with (or to) the school management team. Diverse teams of varying viewpoints are a critical structure for completely exploring ICT integration ideas, and to date, these teams do not yet exist in schools. This opens the way for professional societies and associations to take on critical developmental roles in the formulation and lobby for future direction. Each school's ability to foster, nurture and synthesise the impact of various views of information is also critical to its survival. Low ICT integration schools in this study are already pointing to the existence of an emerging digital divide, one in which some schools will lack the infrastructure and architecture to move to a whole school approach to ICT teaching and learning, and in real terms, face the prospect of being left behind.

\section{References}

Australian Education Council (AEC) (1989). Australia's Common and Agreed Goals for Schooling in the Twenty-first Century: The 1989 Common and Agreed Goals for Schooling in Australia (The 'Hobart Declaration')

http: / / www.mceetya.edu.au/hobdec.htm [viewed 24 July 2005, verified 8 Oct 2006 at http: / / www.mceetya.edu.au/ mceetya/ default.asp?id=11577] 
Barone, C.A, Hagner, P.R (Eds) (2000). Technology enhanced teaching and learning. Price Waterhouse Coopers.

Baskin, C. \& Anderson, N. (2003). The butterflies of the MLE and how to get them flying in formation. Pearson Education Commissioned Paper. Frenchs Forrest. NSW.

Bitner, N. \& Bitner, J. (2002). Integrating technology into the classroom: Eight keys to success. Journal of Technology and Teacher Education, 10(1), 95-100.

Brown, M. (2004). Telling tales out of school: Why ICT is problematic. Invitational Address at CODENZ, Auckland College of Education, 25 March.

Brown, M. (2005). Personal communication. July 2005.

Conlon, T. \& Simpson, M. (2003). Silicon Valley versus Silicon Glen: The impact of computers upon teaching and learning: a comparative study. British Journal of Educational Technology, 34(2), 137-150.

Cuban, L. (2001). Oversold and underused - computers in the classroom. Cambridge, Massachusetts: Harvard University Press.

Department of Education, Training \& Youth Affairs (DETYA) (2000) Learning for the knowledge society. An education and training action plan for the information economy. http:/ / www.detya.gov.au/schools/publications/reports/learning/learning.htm [viewed 12 April 2001, verified 8 Oct 2006 at http:/ / www.dest.gov.au/ sectors/school_ education/publications_resources / profiles/learning_for_the_knowledge_society.htm]

Department of Communication, Information Technology and the Arts. Australia's Strategic Framework for the Information Economy 2004-2006: Opportunities and Challenges for the Information Age. http:/ / www.dcita.gov.au/ie/framework [viewed 9 Jun 2004, verified 8 Oct 2006 at http:/ / www.dcita.gov.au/_data/ assets / pdf_file/20457/New_SFIE_July_2004_final.pdf]

Department of Education (Tasmania) (2002). ICT in education strategic policy 20022005. [viewed 24 Jul 2005, not found 8 Oct 2006] http: / / connections.education.tas. gov.au/attachments / 00000001/ICT\%20in\%20Schools\%20final.doc

Department of Education, Science and Training (DEST) (2005). School education summary. [viewed 12 Sep 2005, verified 8 Oct 2006] http:/ / www.dest.gov.au/ sectors/school_education/School_education_summary2.htm

Guha, S. (2003). Are we all technically prepared? Teachers' perspective on the causes of comfort or discomfort in using computers at elementary grade teaching. Information Technology in Childhood Education Annual, 317-349.

Hagner, P. \& Schneebeck, C. (2000) Engaging the faculty. In C. Barone \& P. Hagner (Eds), Technology-enhanced Teaching and Learning: Leading and Supporting the Transformation on Your Campus. Educause.

Henderson, M. (2004). Investigating how a virtual learning environment can sustain the professional development of teachers: Promoting effective teaching with ICT. PhD Confirmation Seminar. Townsville, November 2004.

JISC (Joint Information Systems Committee) (2003). Strategic Activities: Managed Learning Environments. http:/ / www.jisc.ac.uk/ [viewed 24 Jul 2003, not found 8 Oct 2006]

Loveless, T. (1996). Why aren't computers used more in schools? Educational Policy, 10(4), 448-467. 
Lim C.P., Khine M. S., Hew, T., Wong, P., Shanti, D. \& Lim, B. (2003). Exploring critical aspects of information technologies integration in Singapore schools. Australian Journal of Educational Technology, 19(1), 1-24.

http: / / www.ascilite.org.au/ajet/ajet19/lim.html

Ministerial Council on Education, Employment, Training and Youth Affairs (MCEETYA) (2003). Learning in an online world: Learning Architecture Framework. Curriculum Corporation, Melbourne Australia.

http:/ / www.mceetya.edu.au/verve/_resources/25aagenda.pdf

Ministerial Council for Education, Employment, Training and Youth Affairs (MCEETYA) (2003). Research Strategy: Learning in an online world. http: / / www.mceetya.edu.au/verve/_resources/16aagenda.pdf

Ministerial Council for Education, Employment, Training and Youth Affairs (MCEETYA) (2003). Bandwidth Action Plan: Learning in an Online World. http: / / www.mceetya.edu.au/verve/_resources/47aagenda.pdf

Ministerial Council for Education, Employment, Training and Youth Affairs (MCEETYA) (2005). Joint Statement on Education and Training in the Information Economy. http: / / www.dest.gov.au/ministers/images/js.pdf [viewed 24 Jul 2005, verified 8 Oct 2006]

Ministerial Council on Education, Employment, Training and Youth Affairs (MCEETYA) (2006). Leadership Strategy: Learning in an Online World. http:// www.mceetya.edu.au/verve/_resources/Leadership_Strategy.pdf

Ministerial Council on Education, Employment, Training and Youth Affairs (MCEETYA) (2006). Content Specifications Framework: Learning in an Online World. http:/ / www.mceetya.edu.au/verve/_resources/Content_Specifications_Framework.pdf

Rogers, E. (1995). Diffusion of Innovations. 4th Edition. New York. The Free Press.

Siemens, G. (2004). Connectivism: A learning theory for the digital age. Elearnspace. http:/ / www.elearnspace.org/Articles/connectivism.htm [viewed 17 Oct 2005, verified 8 Oct 2006]

State of Victoria (Department of Education, Employment \& Training) (2001). Information and Communication Strategy 2000-2004. Melbourne: State of Victoria.

Wellman, B. (2001). Computer networks as social networks. Science, 293(14 Sept), 2031-2034.

Zhao, Y., Pugh, K., Sheldon, S. \& Byers, J. (2002). Conditions for classroom technology innovations. Teachers College Record, 104(3), 482-515.

Dr Colin Baskin, School of Education, Cairns Campus, James Cook University, PO Box 6811, Cairns QLD 4870, Australia.

Email: colin.baskin@jcu.edu.au

Michelle Williams, ACCE Fellow, Queensland Society for Information Technology in Education (QSITE), PO Box 8, Red Hill QLD 4059 Australia. Email: shellyw@gil.com.au Web: http:/ / www.qsite.edu.au/ 